\title{
Scientific Perspectivism and psychiatric diagnoses: respecting history and constraining relativism
}

\section{Sam Fellowes ${ }^{1}$ (DD}

Received: 30 August 2019 / Accepted: 28 August 2020 / Published online: 27 October 2020

(C) The Author(s) 2020

\begin{abstract}
Historians and sociologists of psychiatry often claim that psychiatric diagnoses are discontinuous. That is, a particular diagnoses will be described in one way in one era and described quite differently in a different era. Historians and sociologists often draw epistemic consequences from such discontinuities, claiming that truth is pluralistic, provisional and historicised. These arguments do not readily fit in with how analytical philosophers of science approach scientific realism. I show how the pessimistic meta induction does not capture the point which historians and sociologists are making but scientific perspectivism seems to capture their point much better. I then highlight conceptual innovations which scientific perspectivists add. They demarcate between truth and objective reality, they specify which type of truth they endorse and they put down constraints on possible truths. This blocks an anything goes relativism which historians and sociologists can be in danger of falling into. I highlight my argument by discussing a discontinuous episode in the history of autism. I discuss three aspects of this discontinuity and show how scientific perspectivism can portray each aspect as non-trivially true. My argument shows that we can be scientific realists about autism even if we can formulate notions of autism in quite different ways.
\end{abstract}

Keywords Philosophy of psychiatry $\cdot$ Scientific realism $\cdot$ Perspectivism $\cdot$ Models $\cdot$ History of autism

This article belongs to the Topical Collection: Perspectivism in science: metaphysical and epistemological reflections

Guest Editor: Michela Massimi

Sam Fellowes

m.fellowes1@lancaster.ac.uk

1 Politics, Philosophy and Religion, County South, Lancaster University, Lancaster LA1 4YL, UK 


\section{Introduction}

This paper argues that scientific perspectivism offers a useful way to think about psychiatric diagnoses. Scientific perspectivism offers a view of scientific knowledge whereby we can both (i) take knowledge claims seriously, and (ii) accommodate scientific theories being historically situated and replaced over time. Applying scientific perspectivism to psychiatric diagnoses provides a framework which respects historical and sociological studies of psychiatry whilst simultaneously retaining a non-trivial notion of truth.

Historians and sociologists of psychiatry often claim that psychiatric diagnoses are constrained or constituted by the historical era in which they are formulated (Danziger 1997, p.181; Evans 2017, p.8; Hollin 2014, p.2; Rose 1999, p.xiv; Verhoeff 2013, p.443). As history changes, so too the diagnoses which psychiatrists postulate have changed. Additionally, this process will likely continue into the future. Historians and sociologists sometimes draw epistemological claims from such changes, although their claims can prove hard to situate within the positions that have been developed by philosophers. In this paper I will draw upon perspectivism to analyse the relationship between changes in psychiatric diagnoses and notions of truth.

Scientific perspectivism offers useful conceptual tools for understanding how historical changes relate to truth. Firstly, a distinction between objective reality and truth can be made. Truth is partly dependent upon scientists, but objective reality is not (Massimi 2018a, p.170). Secondly, scientific perspectivism supports a notion of truth that fits well with historical change, namely a human-centred rather than an all seeing 'god's eye' view of truth (Giere 2006, p.15; Massimi 2018a, p.165). Thirdly, perspectivists can offer criteria which ensure that there are constraints upon which scientific theories can count as true. This blocks an 'anything goes' relativism where truth is simply what scientists happen to believe at any particular period (Giere 2006, p.66; Massimi 2018a, p.172; Massimi 2018b, p.357). These conceptual developments allow scientific perspectivism to endorse a non-trivial notion of truth which is relative to perspectives, thereby respecting history, but where scientists cannot simply make-up their own truths, thereby constraining relativism.

The long history of scepticism about psychiatry makes questions concerning notions of truth in psychiatry particularly urgent. There are concerns that psychiatric diagnoses are formulated on subjective opinion rather than on scientific evidence (Horwitz 2002, p.5; Kendell and Jablensky 2003, p.7). Psychiatric diagnoses have been described as invented, constructed, arbitrary or made-up (Burrows 2010, p.252; Cushing 2013, p.38; Gains 1992 p.4; Horwitz 2002, p.11; Kinderman et al. 2013, p.2; Summerfield 2001, p.95; Watson 2019, p.2). Additionally, there are calls to significantly revise psychiatry. This includes calls to replace currently employed psychiatric diagnoses with new, alternative diagnoses (Cooper 2005, p.150; Kozak and Cuthbert 2016, p.960; Murphy 2006, p.10) and calls to completely abandon using psychiatric diagnoses altogether (Boyle 1990, p.166; Johnstone 2019, p.15; Read 2004a, p.48; Vanheule 2017 , p.205). Claims that any particular claim posited by psychiatry is, or is not, true and claims that psychiatry has a particular type of truth, have significant potential to influence how psychiatry is viewed. It is thus important to apply recent research in philosophy of science, in particular the development of scientific perspectivism, to discussions of truth within psychiatry. Whether they endorse scepticism themselves or 
not, I suggest that the sociologists and historians I discuss offer few resources to avoid their account falling into scepticism. They offer insufficient resources to determine when a sceptical attitude is justified and when it is not. In contrast, I argue that scientific perspectivism is able to accommodate scientific claims being historically situated and changing over time whilst still offering resources to determine when a sceptical attitude is applicable and when it is not.

I start by outlining how historical research that evidences discontinuities in knowledge claims is sometimes taken to have epistemic consequences. I then compare such arguments to the pessimistic meta induction and scientific perspectivism. I suggest scientific perspectivism can be used to make sense of at least some histories of discontinuity in psychiatry, and illustrate this claim using a discontinuous episode in the history of autism.

\section{Truth and discontinuities}

The history of a particular psychiatric diagnosis can be considered to be, in varying degrees, continuous or discontinuous. Continuity is where there is "a more or less chronological, linear and progressive development towards current understandings" (Verhoeff 2013, p.442). In such cases there has been stability of scientific concepts across the history of a discipline or the only significant changes consist in progress towards the truth. Discontinuity is where present scientific concepts are the latest in a series of significant changes across the history of a discipline and there is no reason to believe modern concepts are superior to past concepts (see Danziger (1997), Foucault (2001) and Shorter (2015)). Discontinuities have been shown in relation to multiple diagnoses such as post-traumatic stress disorder (Young 1995), schizophrenia (Berrios et al. 2003) and the diagnosis which I will focus upon: autism (Evans 2017, p. 240; Eyal et al. 2010, p.209; Feinstein 2010, p.265; Hollin 2014, p.3; Silverman 2012, p.130; Verhoeff 2013, p. 444). Often, historians and sociologists provide less detail than is ideal for philosophically analysing their conceptual claims (they are, of course, writing history and sociology rather than philosophy). Compared to how philosophers approach these issues, it seems they sometimes gesture towards philosophical views in a manner that glosses over distinctions which a philosopher might prefer to demarcate.

For example, note that the distinction between continuity and discontinuity is very broadly drawn. Linearity and progression are linked together (as in the Verhoeff quote), but progress and linearity should plausibly be distinguished. A theory might be modified in a linear way and yet end up worse. Alternatively, a major discontinuity might take place, yet the change might be progressive. Also, philosophers of science have developed many different ways to understand theory change, demarcated many different ways in which changes can take place, and it is unclear exactly how these relate to the sociologists' and historians' notions of 'discontinuity'. This is important because different philosophers place importance upon different aspects of theories being retained. Some scientific realists focus upon the working posits of a theory (Psillos 1999), a structural realist (Ladyman 1998) will focus upon structure, and an entity realist (Cartwright 1999) will focus upon the dispositions (or properties or capacities) of entities. 
Historians and sociologists of psychiatry often discuss notions of truth but typically take quite a different approach to philosophers of science. For example, historian and sociologist of psychiatry Nicholas Rose discusses notions of truth within psychiatry. However, he is concerned

not with truth in some philosophical sense, but with the ways in which systems of truth are established, the ways in which true statements are produced and evaluated, and with the 'apparatus' of truth - the concepts, rules, authorities, procedures, methods and techniques through which truths are realized (Rose 1999 p.4).

Rose talks of how truths are produced and realized rather than about how psychiatrists discover truths. Consider also how in his history of post-traumatic stress disorder (PTSD) Young claims that PTSD "is not timeless, nor does it possess an intrinsic unity. Rather, it is glued together by the practices, technologies, and narratives with which it is diagnosed, studied, treated, and represented and by the various interests, institutions, and moral arguments that mobilized these efforts and resources" (Young 1995, p.5). Despite this, Young considers PTSD as being real and aims to "explain how it [PTSD] and its traumatic memory have been made real, to describe the mechanisms through which these phenomena penetrate people's life world, acquire facticity, and shape the self-knowledge of patients, clinicians, and researchers" (Young 1995, p.6 emphasis original). In Young's view, PTSD is real even though it had to be made real. Similarly, after outlining "conceptual discontinuities" (Verhoeff 2013, p. 444) and multiple changes to the diagnosis which have occurred across the history of autism, sociologist Verhoeff writes that

in describing the reshaping of the concept of autism, the historicity, provisionality and plurality of knowledge and truth about autism become apparent. As a consequence, such a historical reflection destabilizes the present 'truth' about autism as a neurodevelopmental spectrum disorder of social cognition localized in an individual's brain, and as it destabilizes the present 'truth' it creates space for other possible perspectives and conceptualizations of autism in the present and future. The point is, however, not to dismantle the very idea of autism, but merely to correct a positivist and essentialist understanding of autism as a discrete and stable entity in nature that we get to know and understand better and better as science progresses and knowledge accumulates (Verhoeff 2013 p. 455).

For Verhoeff the truths psychiatrists attain are pluralistic, provisional and historicised truths.

Rose, Young and Verhoeff do not talk of truth in a manner which reflects how philosophers of science typically approach the scientific realism debate. Nevertheless, their claims seem to have significant, if not fully explained, epistemological implications. Their claims have some relationship to scientific realism because they seem to see psychiatrists as attaining (or perhaps producing) truths. However, the type of truth attained does not appear to fit with typical scientific realism which does not easily fit 
notions of produced, historicised, provisional or pluralistic truths. At the same time there is some similarity with anti-realist claims, in that currently posited psychiatric diagnoses will not be the one, true set of correct ones. However, anti-realists in philosophy of science typically place significant constraints on what constitutes good science. They typically oppose 'anything goes' views and do not consider all scientific theories as being equally good (Laudan 1984, p.33). In contrast, it is unclear what constraints there are on historicised, provisional, pluralistic and produced truths. Consequently, it is unclear what, if anything, demarcates such an account of truth from an extreme 'anything goes' relativism whereby all claims posited by psychiatrists are equally good.

One potential danger with an 'anything goes' relativism in this area is that it might lead to a scepticism about psychiatric diagnoses. Critics of psychiatry often note that psychiatrists keep revising their diagnostic systems, and argue that current diagnoses are shaped by no more than fad or fashion. Critics take this to mean that psychiatric diagnoses are "made-up" (Watson 2019, p.2), "arbitrary" (Horwitz 2002, p.11; Cushing 2013, p.38), “constructed” (Gains 1992 p.4; Summerfield 2001, p.95), “arbitrarily constructed" (Burrows 2010, p.252), and an "invention" (Read 2004b, p.21; Summerfield 2001, p.95). Of course, scepticism might actually sometimes be the most plausible stance to take towards psychiatric diagnoses, but it would be helpful if resources were available to more precisely specify the circumstances under which scepticism was justified. Unless one adopts a blanket scepticism towards all psychiatric diagnoses then there must be some way to distinguish those diagnoses where scepticism is appropriate from those where it is not.

I draw upon recent work in philosophy of science in search of adequate resources and, as I outline in section three, I show that scientific perspectivism offers these resources. I will apply my discussion of perspectivism to the work of Verhoeff (2013) who has written a recent history of autism. This will allow me to make a detailed analysis of his claims regarding truth and knowledge in psychiatry. In his work Verhoeff argues that there have been changes to notions of autism across three periods, roughly the 1940s to 1960s, the 1960 s to 1980 s, and 1980 s to the present day. He uses his historical analysis to claim that posited truths about autism are historically embedded, plural and provisional. In section 4 I will make a detailed analysis of the historical episodes from which he draws his conclusions to explore how compatible it is with a perspectival reading.

Verhoeff does not define his terms when talking about truth and it is not completely clear why he thinks historical changes support his claims regarding knowledge and truth. The quoted paragraph from Verhoeff is the most concrete characterisation he offers but leaves his exact argument and commitments somewhat unclear. Verhoeff's argument seems partly epistemic. Changes across history are taken to undermine the idea that there is progress in understanding autism. However, the mere fact of change in knowledge claims cannot undermine scientific realism since a change might consist in moving from an incorrect to a correct understanding of autism. His argument also seems metaphysical. Changes across history are taken to undermine "essentialist understanding of autism as a discrete and stable entity" (Verhoeff 2013, p.445). However, changes across history does not entitle this claim. There might actually be a stable, essentialist entity which psychiatrists could potentially succeed in describing one day, even if so far they have failed to do so. Verhoeff needs more argument to link changes across history with his claims about knowledge, truth and essentialism. 
Verhoeff's (2013) claims about pluralities of truths and knowledge are also unclear. Taken literally, he seems to claim that there are multiple truths, rather than a single truth, which a particular knowledge claim might capture. However, are all the pluralistic truths genuine truths or are some truths more genuine than other truths? Notably, Verhoeff puts the word 'truth' in inverted commas but the relevance of this is also obscure. It might be that he is sceptical of the usefulness of all talk of truth in psychiatry. Would, however, this be because he believes psychiatrists could never establish truths in psychiatry (their claims are not truth apt) or merely that he doubts psychiatry has established any truths?

In seeking to charitably reconstruct Verhoeff's argument, I will compare it with some work found in philosophy of science which has at least some superficial similarities. I firstly consider an argument against scientific realism known as the pessimistic meta induction (PMI). I will suggest that on examination this well known argument does not capture the argument Verhoeff aims to make. I will then suggest the less well known notion of scientific perspectivism better fits Verhoeff's approach.

The PMI is usually employed in response to the no miracles argument in debates for and against scientific realism (see Psillos 1999 for an overview). Briefly, the no miracles argument claims there are only two possible reasons for the success a particular theory: either the theory is true or a miracle has occurred. Since miracles are not an acceptable explanation within philosophy the only acceptable explanation is that the theory is true. In response, the pessimistic meta induction identifies historically employed theories which made miracle like predictions yet turned out to be false. Therefore, a theory being successful does not entail that it is true.

This rough sketch of the PMI shows superficial similarities to Verhoeff's argument. Both use as evidence the history of science, showing how scientists from earlier eras believed in theories which are now taken to be incorrect. This suggests that Verhoeff might be considered to be an anti-realist; changes across history gives good reason to doubt that psychiatrists accurately describe the world.

However, considering some of the details of the PMI gives reasons to doubt this interpretation. Notably, the PMI focuses on theories that could have been judged successful on some criteria such as ability to make predictions (Laudan 1981, p.33). In contrast, Verhoeff does not focus only on successful past theories. It seems that changes across history means truths are pluralistic for Verhoeff regardless of what qualities a particular theory might have. Secondly, Verhoeff talks of truth being historicised. This seems to mean that truths are constrained or constituted by wider factors which are present in a particular historical era. In contrast, the PMI is usually employed independently of historical analysis of wider socio-cultural conditions. The success of a theory does (according to no miracles) or does not (according to PMI) entail the truth of a theory regardless of the wider conditions which produced the theory. The differences between his argument and the PMI, mean that the PMI does not seem to capture the point Verhoeff is trying to make. He sees truth as historicised and he offers no grounds to move from historicised truths to non-historicised truth, whereas the PMI is employed to undermine the truth of scientific theories rather than portray them as historicised truths. Beyond the appeal to history, his argument seems to have little commonality with a PMI based anti-realism. I now suggest that Verhoeff's position seems closer to the spirit of, and can be more easily reconstructed to fit, a form of perspectival realism. To show this I now outline scientific perspectivism. 


\section{Scientific Perspectivism}

Scientific perspectivism is typically intended as a form of scientific realism which aims to accommodate the claims that we do not have unmediated access to the external world and that scientific knowledge is situated. Perspectivism typically traces its intellectual heritage to Kant and Nietzsche but I shall focus upon Ronald Giere's work and recent developments by Michela Massimi.

Scientific perspectivism is intended as a moderate form of scientific realism which retains notions of truth and objectivity whilst simultaneously respecting actual scientific practise. Giere writes that perspectivism "mediates between the strong objectivism of most scientists, or the hard realism of many philosophers of science, and the constructivism found largely among historians and sociologists of science" (2006, p.3; also see Massimi 2018a, p.164 \& p.167). This middle ground sees scientific theories as potentially true whilst simultaneously seeing aspects of truth as relativised to a perspective.

Scientific perspectivism is contrasted with views of the world which are perspective independent. Perspectivism sees all knowledge as being dependent on the human perspective. All knowledge claims will be limited to perceptual and cognitive capacities of humans. This contrasts with a hypothetical 'God's eye' view of the world where there is no limitation on how the world is viewed (Giere 2006, p.15; Massimi 2018a, p.165). Additionally, scientific perspectivism adds to this basic claim by seeing scientific truths as being limited to or constrained by the practices of specific scientific communities. Two different scientific communities which adopt significantly different practices would be considered to be in different perspectives.

The scientific practices which constitute different perspectives can be characterised by "specific choices of instruments, theoretical apparatuses, and measurement techniques idiosyncratic to any given scientific community at any given historical time" (Massimi 2018a, p.166) as well as the adapted "standards of performance adequacy that a scientific knowledge claim has to satisfy" (Massimi 2018a, p.172 italics in original). Perspectives can be characterised by different measurement techniques and instruments. Scientists working in one perspective may measure an aspect of the world in a particular way whereas scientists working in a different perspective may measure that same aspect in a different way. Different equipment might be used, and different factors might be considered incidental and so shielded off. Perspectives are also characterised by methodological approaches. Two different approaches might employ different methodologies when modelling data or when assigning causal priority to causal factors. Perspectives can also endorse different theoretical assumptions, such as a classical physics perspective or a quantum physics perspective. Additionally, two different perspectives might employ a different standard for assessing knowledge claims.

This initial sketch of perspectivism seems a more promising means of capturing Verhoeff's approach compared to the PMI. Scientific perspectivism sees scientific communities as occupying different perspectives. These perspectives have different theoretical, experimental, methodological and epistemic commitments, they influence which claims scientists believe to be true and different eras typically have different perspectives. This seems a fruitful way to make sense of Verhoeff's claim about "the historicity, provisionality and plurality of knowledge and truth about autism" (Verhoeff 
2013, p.455). Additionally, whereas the PMI takes changes across history as a threat to truth, Verheoff seems to think changes across history are compatible with some type of truth. Similarly, perspectivists accept that there can be multiple, different, yet realist descriptions of the same target (Giere 2006, p.192; Massimi 2018a, p.168).

Verhoeff's position seems easily open to relativist and sceptical interpretations. Scientific perspectivists offer three conceptual innovations which avoids their position being relativism or scepticism. Firstly, it can block an extreme relativism. Unless someone is an extreme relativist who thinks that literally everything changes (such as the size of the universe) when scientists adopt new views then something must be demarcated as not being dependent upon our views. Perspectivists specify which elements they consider to be non-perspectival. Massimi demarcates between objectivity and truth (Massimi 2018a, p.170). There is only one objective reality. That reality might be considered the non-relativised, perspective independent God's eye view. We can only have perspective dependent views of that reality. Similarly, Giere accepts that there is a "real world" (Giere 2006, p.62) which we can have multiple perspectives of. It could be responded that scientific perspectivists have assumed rather than argued that there is something perspective independent. This is an assumption that I am willing to make. Even the leading scientific realist Stathis Psillos admits that one need assume the world can be described in realist terms; it cannot be argued for (Psillos 2011, p.312). If this assumption is acceptable to realists then it seems acceptable to perspectivists.

Secondly, perspectivism gives an account of how perspectival truths relate to the non-perspectival, objective, real world. This blocks relativism and allows a moderate form of scientific realism because there is both a real world and scientific theories can relate to that world. Ronald Giere argues that truth is similarity between a model and an aspect of the world. Rather than employ typical notions of correspondence with the world he instead employs the much more metaphysically minimal notion of goodness of fit. He argues that no one model can fully resemble the world so only degrees of resemblance rather than correspondence are possible. For example, physics cannot specify the exact amount of matter in the universe whilst sciences like chemistry and biology will not attempt to track many aspects of the world such as subatomic particles (2006, p.6). Scientists build models at different degrees of precision which can be idealised or abstract in different ways. Decisions over the desired degree of precision as well as choices over idealising and abstracting will partly depend on the purposes for which the scientists create the model. These choices will then influence the way in which a model has similarity to the world and how similarity is measured. This means truths are perspectival since judgements over similarity are perspectival (2006, p.66).

For Massimi facts are non-perspectival (Massimi 2018b, p.354). They do not change between different scientific perspectives. In contrast, truth conditions are perspectival. A truth condition is the rules which determine truth values. Truth conditions are the rules by which any particular scientific claim is considered to be true or false (the truth values). As can be shown from historical and sociological studies, scientists do not have one means of determining true claims from false claims. Which standards they use to assess scientific claims depends upon the perspective they are taking. On this notion of truth, facts are non-perspectival whereas the rules which are used to assign truth values are perspectival. This means that truth is not relativised to perspectives but the way in which scientists assess whether claims are true is perspectival. This takes on board, as historians and sociologists have emphasised, how scientists have held 
different views upon what constitutes truth without then seeing what is actually true as being relative.

Thirdly, perspectivists place constraints on what can be considered true. Perspectivists need to avoid the danger of endorsing a trivial notion of truth whereby different perspectives licence their own truths, leaving Einstein's physics no more true than Aristotle's (Massimi 2018b, p.347). There needs be grounds to assert that scientists sometimes actually do posit incorrect theories and that theories vary in how accurately they describe the world. Adding constraints upon what is true supplies a way of avoiding an 'anything goes' approach. The most minimal commitment for scientific realism is "getting things right" (Massimi 2018b, p.345). This means that not every scientific theory is taken as describing the non-perspectival world. Scientific perspectivists offer criteria which means scientists do not licence their own truths. It is a variety of realism, despite theories and models being perspectival, because scientific claims can relate (via similarity for Giere and via correspondence for Massimi) to the non-perspectival world. Scientific perspectivism is not relativistic and is realist because it offers constraints which means that some theories should, and other should not, be considered to get things right. It is not anti-realist, in the sense of Van Fraassen's constructive empiricism (Fraassen and Bas 1980), because Van Fraassen produces arguments which makes him doubt that currently formulated theories and models merit belief. He believes that various epistemic arguments for anti-realism (such as the pessimistic meta-induction) are applicable to most theories and models. In contrast, scientific perspectivists, by believing that truth is not incompatible with holding multiple views of a target, do not accept the pessimistic meta induction as grounds for anti-realism (see Giere 2006, p.92). Giere and Massimi believe that some theories and models pass the epistemic criteria they offer.

On Giere's account, truth is similarity with a target system. This is perspectival because, depending on the perspective adopted, theories and models will differ in the degree they have similarity with a target system. Additionally, judgements about similarity are themselves perspectival because similarity can be measured in different ways. Whilst weaker than an objectivist notion of realism, this is not intended as a trivial notion whereby truth purely depends on the views of scientists. The degree to which a model has similarity to the world will partly be based on the model having some resemblance to the actual world. Perspectival truths will need to be constrained by the world in a manner which goes beyond scientists simply licensing their own truths. A posited theory might have very low degrees of similarity in which case it would simply be wrong and not merit belief.

On Massimi's alternative approach, she considers whether standards of performance adequacy (such as simplicity, coherence, novel prediction, identified mechanism etc.) are perspective independent standards for assessing scientific theories. She argues that they cannot play this role. She highlights how scientists have appealed to different standards of performance adequacy at different historical periods (or at the same historical period). It could be responded that regardless of what the history of science shows philosophers can formulate, independent of actual scientific practise, crossperspectival standards of performance adequacy. However, to consider the standards of performance adequacy which philosophers currently discuss as perspective independent virtues would be to merely elevate our perspective as being the correct one (Massimi 2016, p.763). These claims would be limited to a perspective and future 
perspectives might consider different standards of performance adequacy as the correct ones. Despite this, it is still possible to assess whether a scientific claim made in an earlier perspective should be "retained or withdrawn, depending on whether they continue to satisfy their original standards of performance-adequacy when assessed from another (subsequent) perspective" (Massimi 2018a, p.172). For example, "[a]ncient Greek crystalline spheres are no longer part of our current scientific perspective because they have long lost their performance adequacy with respect to their own original standards (e.g. stability of circular orbits, agreement with astronomical data, neat divisions between celestial and terrestrial phenomena, etc.)" (Massimi 2018a, p.172).

These three conceptual innovations can be applied to Verhoeff. It is unclear whether Verhoeff's provisional, historicised and pluralistic truths are actual truths, particularly given that Verhoeff sometimes places scare quotes round 'truth'. In contrast, perspectivists provide a detailed account of how truth relates to the perspectival and the non-perspectival. Finally, his account looks to be at risk of falling into some sort of skepticism, or alternatively an 'anything goes' relativism. Perspectivism, in contrast, places constraints on which posited truths should be seen as actual truths.

\section{Applying perspectivism to the history of autism}

I now outline and analyse two different perspectives which postulated two different, and discontinuous, approaches to autism. These cover two of the three historical periods which Verhoeff discusses (he breaks his history into 1940s to 1960s, 1960s to $1980 \mathrm{~s}$, and $1980 \mathrm{~s}$ onwards; I will discuss the first and third of these eras). ${ }^{1}$ I characterise each perspective by looking at the work of the psychiatrist who developed and promoted each account of autism (Leo Kanner and Lorna Wing). I will firstly discuss the wider setting in which each worked. Then I outline their different perspectives, show how this resulted in different accounts of autism and then apply Giere's criteria of similarity and Massimi's criteria of evidence generated in later perspectives.

\subsection{Two notions of autism}

The background to the first notion of autism is psychiatric thinking in the US and Britain from the mid-1930s to the mid-1970s (see Evans 2017 chapters 1, 2 and 3; Eyal et al. 2010 chapters 4, 5, 6 and 7; Nadesan 2005 chapter 5; Silverman 2012 chapters 1, 2, and 3; Verhoeff 2013). Psychiatrists in the US and Britain often placed significant importance on the subjective, inner psychic life of the individual. They believed that symptoms might be the result of unconscious mental processes, which were conceived of as being dynamic, and changing over time in response to both external environmental factors and internal biological causes (Evans 2017, p.68; Silverman 2012, p.71; Verhoeff 2013, p.446). These ideas were sometimes, though not always, articulated through a psychoanalytical framework, drawing on the ideas of Freud, or of one of his followers. Psychiatric diagnoses were typically intended to play two roles. Firstly, they

\footnotetext{
${ }^{1}$ Verheoff's discussion of the 1960 s to 1980 s is much shorter and involves much less of a contrast with other eras compared the first and third era.
} 
were intended to capture something of the subjective experience of individual patients. This often led to textbooks and diagnostic manuals employing vignettes of patients, or extracts from case studies, to characterise psychiatric diagnoses rather than formal lists of symptoms. Diagnoses were meant to loosely convey the clinical pictures which patients can manifest rather than describe sharply demarcated classes of patients (Mayes and Horwitz 2005, p.260; Shorter 1997, p.178). Secondly, diagnostic categories were often causally demarcated, usually on the basis of a supposed underlying psychological state (e.g. one type of disorder might be taken to be characterised by the utilisation of one psychological defence mechanism, and another by a different psychological defence mechanism). The diagnosis given to a patient thus indicated the supposed presence of some supposedly significant causal factor (Evans 2017, p.269; Shorter 1997, p.178).

Around the 1960s trends started which by the 1980s would result in a very different psychiatry. Firstly, cognitive psychology started being developed as a discipline. Focus shifted from unconscious, dynamic processes to computationally understood modules whereby different parts of the mind are functionally individuated (Evans 2017, p.233; Hollin 2014, p.14; Verhoeff 2013, p.450). This means there was a significant change in how the psychology of patients was conceptualised. Secondly, there was growing interest in genetics and neuroscience as a means of establishing the causal origin of psychiatric diagnoses (Nadesan 2005, p.142; Silverman 2012, p.144). Some psychiatrists came to doubt the scientific validity of psychoanalytical causal explanations and instead came to think that mental illnesses were likely the result of brain abnormalities. They hoped future investigation would discover the specific causes, such as the specific gene, for each diagnosis. Given that such supposed causes were yet to be discovered this led to a move away from an approach that sought to demarcate disorders on the basis of postulated causes, towards one that demarcated disorders purely on the basis of observable symptoms (Blashfield and Keeley 2010, p.325; Evans 2017 p.217; Hollin 2014 , p.4). They hoped that grouping patients on (supposedly) observable symptoms, rather than the (supposedly) non-existent psychoanalytical defence mechanisms, would act as a basis for finding the correct (supposedly biological) causes. Thirdly, comparisons of how psychiatrists employed diagnoses showed that there was often limited agreement over which diagnosis should be applied. This showed that many diagnoses had low reliability (reliability is the degree to which different psychiatrists provide the same diagnosis to the same patient). Concerns about the reliability of diagnosis led to the development of explicit, descriptive, checklists of symptoms that were hoped to make diagnoses more reliable (Decker 2007, p.352; Mayes and Horwitz 2005, p.260; Robins and Guze 1970, p.108). Fourthly, there was growing interest in statistical methods as a means of parsing up the domain of psychopathology (Evans 2017, p.211; Kendell 1968, p.32). With increasing computing power, statistical methods might be employed to reformulate diagnoses on the basis of the observed symptoms of large groups of patients (Robins and Guze 1970, p.108; Mayes and Horwitz 2005, p.256). All these factors lead to a significant shift. With the intention of increasing reliability diagnoses were now intended to be based around observable symptoms rather than unconscious psychological processes.

I now relate these changes to two perspectives on autism. In 1943, Baltimore based child psychiatrist Leo Kanner formulated a diagnosis which he named autism. This covered children who had difficulties relating to other people and often exhibited 
repetitive behaviour. In this regard it has obvious similarities to the modern diagnosis of Autism Spectrum Disorders (ASD). However, there are crucial differences in the symptoms he described. Kanner characterised autism as "an extreme autistic aloneness, that, whenever possible, disregards, ignores, shuts out anything that comes to the child from the outside" (Kanner 1943 p. 242, emphasis original). As Verhoeff emphasises, Kanner associated aloneness with a withdrawal from the world which is a more severe clinical picture than a lack of social intuition and a preference for solitary activities which are associated with the modern diagnosis (APA 2013, p.454). The child does not just struggle to socialise but rather blocks out or reacts adversely to interference from many different aspects of the external world. Kanner also described autistic children as having the symptom 'maintenance of the same' whereby the child wishes the external environment to remain static and wishes no interference with their own routines (Kanner 1943, p.245). This is a significantly more severe clinical picture compared to modern notions of autistic people who dislike unexpected changes and often have quite narrowly focused and obsessive interests (Verhoeff 2013, p.445). There is a very high level of inflexibility and the reactions to changes to the environment can be very severe. Kanner posited these quite specific symptoms, rather than more general symptoms, because he valued clinical nuance (e.g. detailed descriptions of patients and demarcating between different ways patients exhibit behaviour).

The second difference was that Kanner believed autism was closely related to a more commonly diagnosed psychiatric diagnosis named childhood schizophrenia. This also covered children who had difficulties relating to others and who exhibited repetitive behaviour (note that though they were called childhood schizophrenic it was widely recognised that hallucinations were extremely rare. Lauretta Bender, the main advocate for childhood schizophrenia, writes that "[v]erbal hallucinations akin to the adult's are so uncommon as to be of no diagnostic value" (Bender 1947, p.50)). In 1958 Kanner argued that autism and childhood schizophrenia were closely related, sharing many symptoms, except that autism had a few specific symptoms which were usually absent in childhood schizophrenia, autism was rarer and usually had greater levels of impairment (Kanner and Lesser 1958, p.728). By 1969 he would see autism as one of the three subtypes of childhood schizophrenia (Kanner 1969, p.3). To summarise, Kanner saw autism as a rare, usually severe, disorder that was related to but distinct from other forms of childhood schizophrenia. The relationship Kanner saw between autism and childhood schizophrenia was influenced by his goals. Kanner believed that diagnoses should help the clinician gain a nuanced understanding of specific patients. He believed these nuanced diagnoses which fit his clinical experience could be produced through carefully building case studies of patients. Consequently, Kanner favoured classificatory systems that made use of very many different diagnoses, even if this meant that the clinical pictures associated with each diagnosis might only be distinguishable by the expert clinician. ${ }^{2}$

A new notion of autism was formulated by Lorna Wing in the 1970s. This would gradually replace Kanner's notion and would become the major notion employed

\footnotetext{
${ }^{2}$ When Kanner formulated his diagnosis of autism in 1943 he assigned autism a more specific symptom profile compared to childhood schizophrenia and considered them as separate diagnoses (Kanner 1943, p.248). In 1949 he would consider them as "indistinguishable" (Kanner 1949, p.419) before seeing them as related in the 1950 s and a subtype in the 1960 s.
} 
from around the late 1980s onwards. Wing came from a very different perspective to Kanner, largely adopting the changes which had occurred from the 1960s onwards (Evans 2017, p.297; Eyal et al. 2010, p.203 \& 225). Wing believed that it was important for psychiatric disorders to be described in ways that would ensure they could be diagnosed reliably. She employed statistical methods to try to demarcate between disorders rather than demarcating between them on the basis of postulated causes. In setting out her description of autism, Wing conducted a study that looked at children known to a local health service who exhibited social impairments, verbal and non-verbal language impairments or repetitive, stereotyped behaviour (Wing and Gould 1979, p.13). She then investigated what other symptoms were exhibited by these children and statistically analysed the results. She found two groupings stood out. Firstly, there was a group with significant social impairments. Secondly, there was a group with normal sociability but limited intellect. Those in the socially impaired group often had symptoms which were lacking in the sociable but low intellect group. She found that symptoms which had previously been associated with childhood schizophrenia and its subtypes (such as emotional flatness, muteness or echolalia, absence or marked repetitiveness of symbolic activities, and an interest pattern consisting entirely or partly of repetitive activities) occurred in virtually all of the socially impaired group (Wing and Gould 1979, p.20). Since those behaviours were only associated with the socially impaired group, and were not associated with the social but low intellect group, Wing decided to demarcate a new diagnoses (which she named autism) around social impairments. This was intended to replace childhood schizophrenia and its subtypes (Wing and Gould 1979, p.12; see also Evans 2017, p.296). In addition, since the severity of symptoms was correlated with the degree of social skills impairment she decided that autism was a spectrum which could vary from high to low functioning (Wing and Gould 1979, p.26). This meant that many children who would have been previously diagnosed with childhood schizophrenia or its subtypes were now placed upon the autistic spectrum.

The diagnosis Wing proposed differed from Kanner's notion of autism. Wing checked her study to see if any of the groupings she had identified corresponded to groupings that had been picked out by previous psychiatrists. Of all those checked, she could only detect Kanner's autism. However, though Kanner's autism was present, she argued for abandoning Kanner's diagnosis because it was statistically insignificant within her study. She believed that key symptoms she found "did not differentiate those with and without a history of typical [Kanner's] autism. On the other hand, they were very significantly associated with the degree of social impairment" (Wing and Gould 1979, p.22). Consequently, she removed the subtypes, including Kanner's notion of autism. In summary, Wing merged together much of what had previously been distinct types of childhood schizophrenia and reconceptualised them as an autistic spectrum.

Both Kanner and Wing largely reflected the wider environment that they worked in and this partly accounts for why they produced quite different notions of autism. Kanner valued understanding the individual patient, including their particular psychological profile, whereas Wing valued reliable diagnoses which were the product of statistical analysis. Kanner thus produced narrow subtypes which only an expert clinician could distinguish whereas Wing produced very broad, but relatively easy to diagnose, spectrum. 
In line with Wing's approach, the DSM-III (APA 1980, p.375) and the revised edition (APA 1987, p.187) explicitly states that children being diagnosed with autism were previously diagnosed with childhood schizophrenia or its subtypes. By this point the old notion of childhood schizophrenia had been abandoned and focus had moved on to the notion of autism. ${ }^{3}$

It is worth noting that the history above differs from an account of Wing's work that has become prevalent, but is I shall argue inaccurate (I thank an anonymous reviewer for raising this point). Many might consider Wing to have endorsed subtyping the autistic spectrum because she is commonly understood to have introduced Asperger's syndrome to English language psychiatry and to have popularised the diagnosis. However, Wing did not introduce Asperger's syndrome (a point also emphasised by Verheoff (Verhoeff 2013, p.451)). Following Asperger's publication on the syndrome in 1944 his work was largely only known to German and Japanese psychiatry. However, in 1971 Van Krevelen (1971) published a paper on Asperger's syndrome in the first issue of the Journal of Autism and Childhood schizophrenia (the journal which Leo Kanner founded and edited). Thus Wing did not introduce Asperger's syndrome to English language psychiatry. However, she did write an article on Asperger's syndrome in 1981 which did ultimately lead to the popularisation of Asperger's syndrome. Wing, however, was quite explicit in that paper that she did not think Asperger's syndrome was a separate diagnosis to autism or distinct from autism. She writes that "[s]ub-grouping on factors such as level of intelligence (Bartak $\&$ Rutter, 1976) or on degree of impairment of social interaction (DeMyer, 1976; Wing $\&$ Gould, 1979) has more useful practical implications for education and management than any based on the eponymous syndromes [she refers here to previously employed diagnoses, including Asperger's syndrome]" (Wing 1981, p.124). Thus Wing is arguing that there is no important distinction between Asperger's syndrome and the wider autistic spectrum. On the contrary, she is suggesting that other factors are much more important and she is arguing that Asperger's syndrome should not be a separate diagnosis. In later writings she writes that "various workers have tended to the belief that Asperger syndrome and autism are different conditions - quite the opposite of my intention" (2000, p.418). She considered it "ironic" (2000, p.430) that she is often taken as promoting Asperger's syndrome as being somehow distinct from autism. ${ }^{4}$

\subsection{Three discontinuities}

I now consider three different instances of discontinuity which occurred across the changes I have described. The first discontinuity relates to approaches to categorisation. Kanner was 'a splitter', preferring to split diagnoses into subtypes, whereas Wing was

\footnotetext{
3 The findings of Wing's study, specifically that autism varied significantly in severity, were not present in DSM-III notions of autism (APA 1980), which primarily focused upon individuals taken as having low intellect, but they were largely adopted from DSM-III-R (the revised edition) onwards (APA 1987).

${ }^{4}$ Wing's motive for using the term 'Asperger's syndrome' is that it lacked many of the connotations associated with autism. Wing writes that some individuals who she thinks are on the autistic spectrum "are perplexing to parents, teachers and work supervisors, who often cannot believe in a diagnosis of autism, which they equate with muteness and total social withdrawal. The use of a diagnostic term [Asperger's syndrome] and reference to Asperger's clinical descriptions help to convince the people concerned that there is a real problem" (Wing 1981, p.124; see also Wing 2000, p.419-420)). She felt the Asperger's syndrome was an useful way of convincing people they were on the autistic spectrum since it lacked the connotations of "autism".
} 
'a lumper', preferring to employ a smaller number of diagnoses. Kanner placed children into distinct subtypes based on subtle qualitative differences in their symptomatology. In contrast, Wing saw most of these children as being somewhere on an autistic spectrum and differentiated only on the basis of quantitative variation in levels of impairment. Kanner favoured nuanced subtypes because he valued a diagnostic system that when used by experts might be hoped to provide detailed descriptions of patients. In contrast, Wing valued high reliability in diagnosis and so demarcated subtypes simply on level of functioning rather than on the presence of subtle differences in symptomatology (subtypes can reduce reliability because it can be difficult to determine which subtype an individual fits, and an individual might not fit any subtype, or might fit multiple subtypes). Two different perspectives, with different goals, experimental, methodological and theoretical understandings, thus resulted in two different classifications despite both covering individuals exhibiting largely the same behaviour.

The second discontinuity between the approaches of Kanner and Wing relates to how they conceived of the relationship between children they considered autistic, and those children who do hallucinate. From the 1930s to the 1970s some of those rare children who hallucinated were considered to have childhood schizophrenia because they were taken as undergoing psychological processes which had a degree of similarity to non-hallucinating children diagnosed with childhood schizophrenia (Bender 1947, p.41 \& 50). ${ }^{5}$ On Kanner's approach, children who hallucinate, and those he described as having childhood schizophrenia (or one of its subtypes) could have related disorders. In contrast, on Wing's approach children who hallucinate, and those she placed on the autistic spectrum have conditions that are not taken to be related. Following Wing's approach, from the Diagnostic and Statistical Manual Third Edition (DSM-III, the main diagnostic manual used in psychiatry) onwards children who hallucinate would typically meet diagnostic criteria for schizophrenia, a condition that the DSM-III takes to be unrelated to autism and cannot be diagnosed alongside autism (APA 1980, p.375; Cantor et al. 1982, p.758).

A third discontinuity between Kanner and Wing's approaches relates to changes in the symptoms they associate with autism. A symptom which Kanner heavily emphasised was no longer described, or at least heavily reformulated, in Wing's notion of autism. Kanner describes a symptom he named 'maintenance of the same' (Kanner 1943, p.245). Kanner described children who insisted upon their environment remaining near identical. He writes that "[t]he child's behaviour is governed by an anxious obsessive desire for the maintenance of sameness" (Kanner 1943, p.245). They reacted very adversely to any changes to their environment. This does have some similarities to Wing's notion that autistic people exhibit repetitive movements, routines and have a narrow range of obsessive interests (Wing and Gould 1979, p.16). However, Kanner's notion of maintenance of the same was narrower than these symptoms. It specifically related to a need to keep the environment the same and the children he described suffered significant distress when the environment changed. Repetitive behaviours and obsessive interests have many more aspects than, and often do not involve, avoiding changes to the environment or avoiding anxiety (Verhoeff 2013, p.45).

\footnotetext{
${ }^{5}$ Some children who hallucinated were not considered to have childhood schizophrenia if they were believed to not have the underlying psychological approaches associated with childhood schizophrenia.
} 
These variances in views do not easily fit typical scientific realism. A realist would want to know which account of autism is the correct one, and would face the worry that we cannot work out which is the correct one. This would no doubt encourage sceptics of psychiatric diagnoses who see psychiatric diagnoses being made-up and would see Kanner's and Wing's approaches as no better than any random diagnosis a psychiatrist felt like making up. Nothing on Verheoff's approach would block this concern. In response, I draw upon perspectivism to suggest that, by accepting the legitimacy of multiple models, both can be considered true. Also, by showing that they pass epistemic criteria which many made-up diagnoses would fail, we should not adopt scepticism regarding these psychiatric diagnoses.

\subsection{Discontinuity and Perspectivism}

I now consider each of the three discontinuities described above to consider what epistemic consequences should follow from them. I consider what consequences they have for notions of truth and consider whether they should entail scepticism by drawing upon the perspectival realism of Giere and Massimi. I take the behaviour which people exhibit to be the real, objective, non-perspectival target which psychiatric diagnoses, via psychiatric symptoms, aim to describe. I use the word behaviour in the broad sense of not just bodily actions but also activity of the psyche such as feelings and perceptions. If one is willing to accept that there is a mind-independent world then it seems acceptable that there are people in the world and that people are not simply static. Rather, people dynamically engage with and respond to their own psyche and their external environment both in bodily actions and in the activity of the psyche. I call that engagement and response 'behaviour' and consider it real, objective and non-perspectival. Psychologists and psychiatrists can study behaviour in a variety of perspectival manners such as theory-laden observations and experiments. They can also produce perspectival models of that behaviour. Eventually, psychiatrists group various behaviours into perspectival psychiatric symptoms in a manner which will abstract some of the specific details of actual instances of behaviour. For example, there will be particular details relating to any actual instance of social interaction (length of time speaking, manner of speaking, words said) but those particular details are abstracted away by being considered instances of the generalised symptom low social skills (Fellowes 2017a, p.285). Psychiatric symptoms are then grouped together into perspectival psychiatric diagnoses. Somebody who exhibits enough symptoms of a psychiatric diagnosis will receive the diagnosis (sometimes other criteria also need passing). This means the perspectival psychiatric diagnosis will, via perspectival psychiatric symptoms, describe the non-perspectival behaviour. The non-perspectival behaviour of patients were grouped by Kanner and Wing together into perspectival psychiatric symptoms and perspectival psychiatric diagnoses. I now show how, by considering the constraints which Giere and Massimi put on truth, both Kanner's and Wing's approaches can be considered perspectival realist.

The first discontinuity is that Kanner was a splitter, producing subtypes which vary qualitatively, whereas Wing was a lumper, producing a spectrum which demarcated different ways of being autistic purely on severity. Perspectivism can see both perspectives as true. On Giere's approach, both Kanner's approach and Wing's approach have a level of similarity to actual patients. Kanner's approach has similarity because it 
allows each subtype to give more precise descriptions of patients. Wing's approach has similarity because many of the inaccuracies of employing subtypes were removed. Kanner's approach of employing multiple subtypes with different symptomatology increases accuracy but decreases reliability, whereas Wing formulating a spectrum decreases accuracy but increases reliability. Increasing accuracy means that Kanner's subtypes more closely reflect the target (the behaviour of particular individuals) compared to Wing's spectrum. However, increasing reliability reduces the number of times that people are given the incorrect diagnosis, meaning the target is more likely to be correctly considered an instance of one diagnosis rather than mistakenly considered an instance of a different diagnosis. Whether greater accuracy (more closely reflecting the target) or reliability (reducing how often the wrong diagnosis is applied to the target) produces the most similarity to the world depends on perspective dependent views on similarity.

On Massimi's approach, past perspectives can be judged by later evidence. There are multiple recent studies which have tried to detect symptomatically characterised subtypes of the autistic spectrum which do not simply vary in level of severity. Some studies posited possible subtypes (de Gaimbattista et al. 2019, p.147; Fitzgerald 2019, p.4; Lai et al. 2013, p.2; Newson et al. 2003, p.596). However, studies into subtyping typically produce no clear results (Charman et al. 2011, p.12; Munson et al. 2008, p.2). Proposed subtypes typically lack significant statistical strength, they typically overlap with one another and there is usually no obvious reason to favour one set of proposed subtypes above another proposed set. Consequently, any particular individual will typically only loosely fit a particular subtype or will fit multiple proposed subtypes. At the same time, the possibility of subtyping is far from ruled out. The acceptability of subtypes depends upon willingness to sacrifice parsimony and reliability to increase the fit between a diagnosis and at least some patients. As such neither Kanner's nor Wing's approaches can be said to have been disproved by evidence generated in a later perspective.

The second discontinuity is that Kanner did not see children who hallucinate (and who also have some symptoms of childhood schizophrenia) as being importantly different from those with other forms of childhood schizophrenia whereas Wing thought it important to distinguish between those who hallucinate and her autistic spectrum. From Giere's modelling perspective children who hallucinate can either be modelled in a manner which links them to autistic children or in a manner that makes them distinct from autistic children. Some symptoms are common across modern notions of autism and modern notions of schizophrenia (e.g. social withdrawal, difficulties connecting emotionally, oddities in speech, abnormal cognition). In contrast, some symptoms are specific to each group, (e.g. hallucinations are not present in autism whilst repetitive behaviour often takes a quite different form in schizophrenia). Kanner and Wing place different priority on hallucinations. Kanner models in a manner where hallucinations are not considered crucial for demarcation, rather, what binds childhood schizophrenia is a number of related underlying psychological processes (additionally, as I outline in the next paragraph, this is compatible with current evidence). He thought that these underlying psychological processes could occasionally give rise to hallucinations. Consequently, he related together those children who hallucinate and those who do not. In contrast, Wing desired diagnoses which could be reliably diagnosed. She did not think psychiatric diagnoses should be based upon speculation about 
underlying psychological processes. Consequently, she intended to formulate diagnoses based upon which symptoms statistically correlated together. Since hallucinations were statistically insignificant within the autistic spectrum she considered them to be indicative of a different diagnosis. Which approach best models reality depends upon perspective dependent judgements over what types of similarity are considered most important.

Turning to consider Massimi's approach, there is no clear evidence which has been raised in subsequent perspectives which would disprove earlier perspectives. It remains a live debate whether children who hallucinate (and who would now be diagnosed as schizophrenic) should be considered to have a condition related to autism. Around a quarter to half of individuals who meet the diagnostic criteria for childhood onset schizophrenia also meet the diagnostic criteria for an autism spectrum disorder (Rapoport et al. 2009, p.11). Whether one condition can cause the other, can be a risk factor for the other, or whether these are alternative forms of the same disorder is a question which is being investigated (Rapoport et al. 2009, p.12). Many of the cognitive processes which are today associated with the autistic spectrum can be found in individuals diagnosed with schizophrenia, (in relation to theory of mind see Sprong, et al. (2007, p.10), for executive dysfunction see (Orellana and Slachevsky 2013, p.5), for weak central coherence see Happé \& Frith (2006, p.15)). Evidence to date seems compatible with both Kanner's and Wing's approach.

Thirdly, there is the discontinuity over changing symptoms. Kanner posits a symptom of maintenance of the same whereas Wing posited the much more watered down symptoms of repetitions, routines and obsessions. Specific aspects which Kanner describes are absent on Wing's account. On Giere's approach, both Kanner and Wing succeed in fairly well describing the symptoms of the populations they consider autistic. Remember that Kanner's 'autism' is a narrower diagnosis than Wing's. Kanner thought of autism as a rare condition that was a subtype of childhood schizophrenia. In contrast, Wing took most of the children who would have been described as having different types of childhood schizophrenia by Kanner and re-described them as being on the autistic spectrum. I suggest that the difference in populations means that 'maintenance of the same' was indeed a symptom of Kanner's autism, but not of Wing's. Kanner thought that the symptom maintenance of the same was specific to autism, and was only rarely seen in childhood schizophrenia or its other subtypes (Kanner and Lesser 1958). Given the specific behaviour which children with the subtype of autism were exhibiting and given Kanner's goal of clinical nuance there was good reason to posit the symptom maintenance of the same. Wing then removed those subtypes when she formulated the autistic spectrum. When investigating that broad grouping she would have found maintenance of the same to be a rare symptom. The behaviour which was considered instances of maintenance of the same was common within Kanner's narrow subtype of autism whereas it was rare within Wing's much larger autistic spectrum. Consequently, the symptom of maintenance of the same would not meet her standard of statistical significance and so, by that standard, she had no reason to believe it was a symptom associated with the autistic spectrum. Rather, she instead formulated the broader and more nebulous symptoms of repetitive and restrictive behaviour. By being less specific those symptoms would have covered more individuals than maintenance of the same and so were statistically significant within the autistic spectrum. In both cases, the same non-perspectival behaviour is present but 
different perspectives justify describing the behaviour by formulating different symptoms.

Additionally, turning to Massimi's approach, there is no subsequent evidence which would disprove the notions posited by either perspective. Modern evidence suggests repetitive behaviour is a diverse phenomena. It can stem from an autistic individual having an obsessive interest in a narrow area, it can be an attempt to handle anxiety, it can relate to executive dysfunctions, or to difficulty with planning, or to handling unexpected changes etc. (Cuccaro et al. 2003, p.12; Doan and Fenton 2013, p.51; Szatmarie et al. 2006, p.587) There are many different ways these behaviours could be grouped together. No current evidence disproves Kanner's approach or Wing's approach when, judged from their respective perspectives.

\section{Ethical and practical grounds for preferring either perspective}

Having argued that both Kanner's and Wing's perspective are equally acceptable on epistemic grounds I now consider if there are ethical or practical grounds to favour either perspective. Here I will consider which perspective is most clinically useful and most beneficial for diagnosed individuals. Doing this also links perspectivism with issues of science in use. It has been argued that autistic individuals have valuable lived experience which means autistic individuals should play a central role in answering ethical and practical questions (Fletcher-Watson et al. 2019, p.944). As a diagnosed autistic individual my thoughts upon this will have been influenced by my own lived experience (although it should be emphasised that my views are far from representative of all autistic individuals).

For brevity I shall focus upon whether ethical and practical considerations support subtypes or abandoning subtypes. Here I disagree with the claims made by Silberman in his influential popular history of autism book Neurotribes. He argues that subtypes of autism are "prefabricated pigeonholes" (Silberman 2015, p.187) which unrealistically constrain how we think of autistic people. In contrast, when subtypes were abandoned the "full breadth" (Silberman 2015, p.503) of the autistic spectrum was revealed, helping us see the ways in which autism can manifest. Silberman argues this helps us understand autistic people better and helped give those newly identified autistic individuals a voice (Silberman 2015, p.44). ${ }^{6}$

In contrast to Silberman I argue that a non-subtyped spectrum can conceal diversity by de-emphasising rarer aspects. Within a spectrum some characteristics will be relatively common and some will be relatively rare. The more common characteristics will be more prominent compared to the rarer characteristics and so the more common characteristics can conceal rarer characteristics (prominence can also depend upon how overt a characteristic is and how much it is actively promoted in scientific papers, the media and advocacy). In contrast, adding subtypes to a spectrum can reveal those rarer characteristics. A characteristic which is uncommon within a spectrum can be common within a subtype. There can be characteristics which are considered present within both the wider spectrum and the subtype but, given how rare it is within the spectrum, it

\footnotetext{
${ }^{6}$ It is worth noting that I also disagree with many of Silberman's historical claims, especially those relating to Kanner (see Fellowes 2017b; Fellowes 2020a).
} 
gains significant prominence due to it being emphasised by being present in the subtype. Simply thinking of the spectrum does not emphasise the symptom whereas also thinking of the subtype does emphasise it. Alternatively, there can be characteristics which are only formulated when there is sub-typing. An example of this is how maintenance of the same was a common symptom of Kanner's autism and was then removed and reformulated into the weaker symptom of repetitive behaviours and obsessive interests in Wing's autistic spectrum. A subtype was needed for the symptom of maintenance of the same to reach statistical significance so the symptom was no longer formulated in Wing's spectrum.

A symptom being emphasised or formulated due to a subtype has clinical benefits. When a symptom is emphasised then attention is drawn to what is otherwise a rare symptom. This is important because subtle symptoms can go undetected (Fellowes forthcoming). When a more specific symptom is only formulated due to a subtype then a more nuanced understanding of particular behaviour is possible compared to covering that behaviour with a more generalised symptom. Subtyping can also help with understanding diagnosed individuals outside the clinical domain. The notion or notions of autism that people have, especially individuals without psychiatric or psychological training, will be influenced by more prominent aspects of autism. A subtype can increase the prominence of a symptom by emphasising it or if it is only formulated due to the subtype. This will help everyday interactions with autistic people, help media portrayals of autistic individuals, help guide building support services and help guide making reasonable adjustments (Fellowes 2017b, p.57). Finally, subtyping can help give autistic individuals a voice. Scientists or policy makers who wish to consult autistic individuals could ensure they gain a more representative picture of autism if they sought out individuals with subtypes. It would also help autistic advocates represent multiple ways of being autistic. Speaking from personal experience, having a desire to ensure that I represent multiple ways of being autistic when advocating, rather than merely presenting my own way of being autistic as representative of autism in general, does relatively little to inform me of what other ways there are of being autistic. Had I been able to refer to subtypes then I would have guidance over the various ways in which autism can manifest (Fellowes 2020b, p.45).

\section{Conclusion}

Sociologists and historians, such as Verhoeff, Rose and Young, have made important observations about the ways in which knowledge claims vary over time in science. Whilst insightful, their discussions do not readily translate into those concerning scientific realism as discussed by philosophers of science. In this paper I have shown how scientific perspectivism can accommodate notions of truth being relativised to historical eras whilst still retaining a form of scientific realism.

Scientific perspectivism can be of use in developing a framework for applying notions of truth to psychiatry. I suggest that scientific perspectivism offers significant resources to block the risk of an extreme relativism by demarcating between truth and objective reality. It also puts down constraints upon what counts as a truth in the form of Giere's criteria of similarity and Massimi's criteria of evidence gathered in other perspectives. This is important because it is easy to take discontinuous changes as 
reason to be sceptical about current psychiatric diagnoses. Unless one advocates for a blanket scepticism there needs to be some way of determining when scepticism is reasonable and when it is not. Many critics consider psychiatric diagnoses to be arbitrary constructs and made up inventions rather than legitimate scientific knowledge. This has lead to calls to abandon using psychiatric diagnoses, including autism. I have shown that historical evidence which demonstrates discontinuities in thinking about autism need not support such claims. For scientific perspectivists, past views regarding autism can differ significantly from present views, with neither being wrong.

Scientific perspectivism is not problem free. Scientific perspectivists have argued that perspectivism is a unique position but how successful it is can certainly be debated. It needs walk a tight line to avoid falling into non-perspectival scientific realism or into anti-realism (Chakravartty 2010, p.409; Morrison 2011, p.351). Scientific perspectivism, in the forms outlined by Giere and Massimi, is a relatively new approach so if these issues can be resolved then this will likely be some time in the future. Additionally, even if scientific perspectivism collapses into other positions, the constraints upon truth I have discussed may still be useful ways to assess historical and sociological changes and block an 'anything goes' relativism even if there is still the outstanding question of whether passing them delivers full scientific realism or antirealism.

Acknowledgments I would like to thank Rachel Cooper, Jane Pitt and George Turner who read and offered helpful criticism of this article. I am a Wellcome Trust funded Research Fellow [209868/Z/17/Z].

Open Access This article is licensed under a Creative Commons Attribution 4.0 International License, which permits use, sharing, adaptation, distribution and reproduction in any medium or format, as long as you give appropriate credit to the original author(s) and the source, provide a link to the Creative Commons licence, and indicate if changes were made. The images or other third party material in this article are included in the article's Creative Commons licence, unless indicated otherwise in a credit line to the material. If material is not included in the article's Creative Commons licence and your intended use is not permitted by statutory regulation or exceeds the permitted use, you will need to obtain permission directly from the copyright holder. To view a copy of this licence, visit http://creativecommons.org/licenses/by/4.0/.

\section{References}

APA. (1980). Diagnostic and statistical manual of mental disorders (3 ${ }^{\text {rd }}$ ed). Washington, DC: American Psychiatric Association.

APA. (1987). Diagnostic and statistical manual of mental disorders ( $3^{\text {rd }}$ ed revised). Washington, DC: American Psychiatric Association.

APA. (2013). Diagnostic and statistical manual of mental disorders ( $5^{\text {th }}$ ed). Washington, DC: American Psychiatric Association.

Bender, L. (1947). Childhood schizophrenia: A clinical study of 100 schizophrenic children. American Journal of Orthopsychiatry, 17, 40-56.

Berrios, G. E., Luque, R., \& Villagran, J. M. (2003). Schizophrenia: A conceptual history. International Journal of Psychology and Psychological Therapy, 3(2), 111-140.

Blashfield, R. K., \& Keeley, J. (2010). A short history of a psychiatric diagnostic category that turned out to be a disease. In T, Millon., R. Krueger., \& E. Simonsen (Eds), Contemporary Directions in Psychopathology, Scientific Foundations of the DSM-V and ICD-11. New York: Guilford.

Burrows, K. (2010). What epidemic? The social construction of bipolar epidemics. Advances in Medical Sociology, 11, 243-261.

Boyle, M. (1990). Schizophrenia: a scientific delusion? London: Routledge. 
Cantor, S., Evans, J., Pearce, J., \& Pezzot-Pearce, T. (1982). Childhood schizophrenia: Present but not accounted for. American Journal of Psychiatry., 139(6), 758-762.

Cartwright, N. (1999). The dappled world. Cambridge: Cambridge University Press.

Chakravartty, A. (2010). Perspectivism, inconsistent models, and contrastive explanation. Studies in the History and Philosophy of Science, 41, 405-412.

Charman, T., Jones, C. R. G., Pickes, A., Simonff, E., Baird, G., \& Happe, F. (2011). Defining the cognitive phenotype of autism. Brain Research, 1380, 10-21.

Cooper, R. (2005). Classifying madness: A philosophical examination of the diagnostic and statistical manual of mental disorders. Dordrecht: Springer.

Cuccaro, M. L., Shao, Y., Grubber, J., Slifer, M., Wolpert, C. M., Donnelly, S. L., Abramson, R. K., Raven, S. A., Write, H. H., DeLong, R. G., \& Pericak-Vance, M. A. (2003). Factor analysis of restricted and repetitive Behaviours in autism using the autism Diagnositic interview-R. Child Psychiatry and Human Development, 34(1), 3-10.

Cushing, S., (2013). Autism: The very idea. In J. Anderson. \& S. Cushing, Simon. (Eds.), The Philosophy of Autism (pp.17-46) Plymouth: Rowman \& Littlefield.

Kinderman, P., Read, J., Moncrieff, J., \& Bentall, R. P. (2013). Drop the language of disorder. Evidence Based Mental Health, 16(1), 2-3.

Kozak, M. J., \& Cuthbert, B. N. (2016). The NIMH research domain criteria initiative: Background, issues, and pragmatics. Psychophysiology, 53, 286-297.

Danziger, K. (1997). Naming the mind: How psychology found its language. London: Sage.

de Gaimbattista, C., Ventura, P., Trerotoli, P., Margari, M., Palumbi, R., \& Margari, L. (2019). Subtyping the autism Spectrum disorder: Comparison of children with high functioning autism and Asperger Syndroe. Journal of Autism and Developmental Disorders, 49, 138-150.

Decker, H. (2007). How Kraepelinian was Kraepelin? How Kraepelinian are the neo-Kraepelinians? - From Emil Kraepelin to DSM-III. History of Psychiatry, 18(3), 337-360.

Doan, M., \& Fenton, A. (2013). Embodying autistic cognition: Towards reconceiving certain "autism-related" Behavioural Atypicalities as functions. In Jami. L, Anderson. \& S. Cushing. (Eds), The philosophy of autism (pp.47-72). Plymouth: Rowman \& Littlefield.

Evans, B. (2017). The metamorphosis of autism. Manchester: Manchester University Press.

Eyal, G., Hart, B., Onculer, E., Oren, N., \& Rossi, N. (2010). The autism matrix. Cambridge: Polity Press.

Feinstein, A. (2010). A history of autism: Conversations with the pioneers. Chichester: WileyBlackwell.

Fellowes, S. (2017a). Symptom modelling can be influenced by psychiatric categories: Choices for research domain criteria (RdoC). Theoretical Medicine and Bioethics, 38(4), 79-294.

Fellowes, S. (2017b). Putting the present in the history of autism. Studies in the History and Philosophy of the Biological and Biomedical Sciences, 61, 54-58.

Fellowes, S. (2020a). The importance of getting Kanner's account right in debates over first descriptions of autism. Journal of Autism and Developmental Disorders, Online ahead of print. DOI: https://doi.org/10. 1007/s10803-020-04470-y.

Fellowes, S. (2020b). Additional challenges to fair representation in autistic advocacy. American Journal of Bioethics, 20(4), $44-45$.

Fellowes, S. (forthcoming). The value of categorical Polythetic diagnoses in psychiatry. British Journal for the Philosophy of Science.

Fitzgerald, Michael. (2019). Empathy: Autism and psychopathy. In M. Kondo (Ed). Empathy study. Intech Open.

Fletcher-Watson, S., Adams, J., Brook, K., Charman, T., Crane, L., Cusack, J., Leekam, S., Milton, D., Parr, J., \& K. \& Pellicano, E. (2019). Making the future together: Shaping autism research through meaningful participation. Autism, 23(4), 943-953.

Foucault, M. (2001). Madness and civilization. Oxon: Routledge.

Gains, A. D. (1992). From DSM-I to III-R; voices of self, mastery and the other: A cultural constructivist Reading of U.S. psychiatric classifications. Social Sciences and Medicine, 35(1), 3-24.

Giere, R. N. (2006). Scientific Perspectivism. Chicago: Chicago University Press.

Happé, F., \& Frith, U. (2006). The weak coherence account: Detail-focused cognitive style in autism Spectrum disorders. Journal of Autism and Developmental Disorders, 36(1), 5-26.

Hollin, G. (2014). Constructing a subject: Autism and human sociality in the 1980s. History of the Human Sciences, 27(4), 1-18.

Horwitz, A. (2002). Creating mental illness. Chicago: University of Chicago Press.

Johnstone, L. (2019). Do you still need your psychiatric diagnosis? Critique and alternative. In J. Watson. (Ed.) Drop the Disorder: Challenging the Culture of Psychiatric Diagnosis (pp.8-23) Monmouth: PCCS books. 
Kanner, L. (1943). Autistic disturbance of affective contact. Nervous Child, 2, 217-250.

Kanner, L. (1949). Problems of nosology and psychodynamics of early infantile autism. American Journal of Orthopsychiatry, 19(3), 416-426.

Kanner, L. (1969). The children Haven't Read those books, reflection on differential diagnosis. Acta Paedopsychiatrica, 36, 2-11.

Kanner, L., \& Lesser, L. I. (1958). Early infantile autism. Pediatric Clinic North America, 5(3), 711-730.

Kendell, R. (1968). Classification of depressive illness. London: Mausdley Monograph.

Kendell, R., \& Jablensky, A. (2003). Distinguishing between the validity and utility of psychiatric diagnosis. American Journal of Psychiatry, 35, 139-144.

Lai, M.-C., Lombardo, M. V., Chakrabarit, B., \& Baron-Cohen, S. (2013). Subgrouping the autism "Spectrum": Reflections on DSM-5. PLoS Biology, 11(4), 1-7.

Ladyman, J. (1998). What is structural realism? Studies in History and Philosophy of Science, 29, 409-424.

Laudan, L. (1981). A confutation of convergent realism. Philosophy of Science, 48(1), 19-49.

Laudan, L. (1984). Science and Values. Berkeley: University of California Press.

Massimi, M. (2016). Three tales of scientific success. Philosophy of Science, 83(5), 757-767.

Massimi, M. (2018a). Perspectivism. In J. Saatsi (Ed.) The Routledge Handbook on Scientific Realism New York: Routledge.

Massimi, M. (2018b). Four kinds of perspectival truth. Philosophy and Phenomenological Research, 96(2), 342-359.

Mayes, R., \& Horwitz, A. V. (2005). DSM-III and the revolution in the classification of mental illness. Journal of the History of the Behavioral Sciences, 41(3), 249-267.

Morrison, M. (2011). One phenomena, many models: Inconsistency and complementarity. Studies in the History and Philosophy of Science, 42, 342-351.

Munson, J., Dawson, G., Sterling, L., Beauchaine, T., Zhou, A., Koehler, E., Lord, C., Rogers, S., Sigman, M., Estes, A., \& Abbott, R. (2008). Evidence for latent classes of IQ in Young children with autism Spectrum disorders. American Journal of Mental Retardation, 113(6), 439-452.

Murphy, Dominic. (2006). Psychiatry in the scientific image. Massachusetts: Massachusetts Institute of Technology.

Nadesan, M. H. (2005). Constructing autism. London: Routledge.

Newson, E., Marechal, K. L., \& David, C. (2003). Pathological demand avoidance syndrome: A necessary distinction within the pervasive developmental disorders. Archives of Disease in Childhood, 88, 595-600.

Orellana, G., \& Slachevsky, A. (2013). Executive functioning in schizophrenia. Frontiers of Psychiatry, 4(35), $1-15$.

Psillos, S. (1999). Scientific realism: How science tracks truth. Oxon: Routledge.

Psillos, S. (2011). Choosing the realist framework. Synthese, 180, 301-316.

Robins, E., \& Guze, S. B. (1970). Establishment of diagnostic validity in psychiatric illness: Its application to schizophrenia. American Journal of Psychiatry, 126(7), 107-111.

Rapoport, J., Chavez, A., Greenstein, D., Addington, A., \& Gogtay, N. (2009). Autism Spectrum disorders and childhood-onset schizophrenia: Clinical and biological contributions to a relation revisited. Journal of the American Academy of Child and Adolescent Psychiatry, 48(1), 10-18.

Rose, N. (1999). Governing the soul: The shaping of the private self 2nd edition. London: Free Association Books.

Read, John. (2004a). The invention of schizophrenia. In Read, John, Loren R Mosher. And Richard P Bentall. Models of Madness, Psychological, Social and Biological approaches to Schizophrenia. Hove: BrunnerRoutledge.

Read, John. (2004b). Does 'Schizophrenia' exist? Reliability and validity. In Read, John, Loren R Mosher. And Richard P Bentall. Models of Madness, Psychological, Social and Biological approaches to Schizophrenia. Hove: Brunner-Routledge.

Shorter, E. (1997). A history of psychiatry: From the era of the asylum to the age of Prozac. New York: John Wiley \& Sons.

Shorter, E. (2015). What Psychaitry left out of the DSM-5: Historical mental disorders today. New York: Routledge.

Silberman, S. (2015). Neurotribes: The legacy of autism and the future of Neurodiversity. London: Atlantic Books.

Silverman, C. (2012). Understanding autism: Parents, doctors, and the history of a disorder. New Jersey: Princeton University Press.

Sprong, M., Schothorst, P., Vos, E., Hox, J., \& Van Engeland, H. (2007). Theory of mind in schizophrenia. British Journal of Psychiatry, 191, 5-13. 
Summerfield, D. (2001). The invention of post-traumatic stress disorder and social usefulness of a psychiatric category. British Journal of Medicine, 332, 95-98.

Szatmarie, P., Georgiades, S., Bryson, S., Zwaigenbaum, L., Roberts, W., Mahoney, W., Goldbert, J., \& Tuff, L. (2006). Investigating the structure of the restricted, repetitive behaviours and interest domains of autism. Journal of Child Psychology and Psychiatry., 47(6), 582-590.

Van Fraassen, Bas. (1980). The scientific image. Oxford: Clarendon Press.

Van Krevelen, D. (1971). Early infantile autism and autistic psychopathy. Journal of Autism and Developmental Disorders, 1(1), 82-86.

Vanheule, S. (2017). Psychiatric diagnoses Revisisted: From DSM to clinical case formulation. Cham: Plagrave McMillian.

Verhoeff, B. (2013). Autism in flux: A history of the concept from Leo Kanner to DSM-5. History of Psychiatry, 24, 442-458.

Watson, J. (2019) Introduction. In J. Watson. (Ed.) Drop the Disorder: Challenging the Culture of Psychiatric Diagnosis (pp.1-7) Monmouth: PCCS books.

Wing, L., \& Gould, J. (1979). Severe impairments of social interaction and associated abnormalities in children: Epidemiology and classification. Journal of Autism and Developmental Disorders, 9(1), 11-29.

Wing, L. (1981). Asperger's syndrome: A clinical account. Psychological Medicine, 11(1), 115-129.

Wing, L. (2000). Past and future research on Asperger's syndrome. In A kiln. F, R, Volkmar. S, S, sparrow. Asperger Syndrome (pp.418-432) London: Guilford press.

Young, A. (1995). The harmony of illusions. Princeton: Princeton University Press.

Publisher's note Springer Nature remains neutral with regard to jurisdictional claims in published maps and institutional affiliations. 